\title{
Gestão hospitalar, sob a lente da Resource Based View (RBV)*
}

\section{Francisco Carlos Cobaito}

Economista, Universidade Presbiteriana Mackenzie (SP) - Especialização em Administração Financeira, Universidade São Judas (SP) - Mestre em Administração, Uninove (SP) - Pesquisador do grupo de estratégia em projetos CNPq - da Universidade Nove de Julho - Uninove (SP).

fcobaito@ig.com.br

RESUMO: Este artigo analisa a experiência do Plano Diretor de Melhoria da Gestão Hospitalar, desenvolvido e aplicado durante o ano de 2007 no Hospital do Rim e Hipertensão. O intuito do projeto foi desenhar um modelo gerencial eficaz para a instituição, que abrangesse tanto a cultura como as ações dos diversos serviços prestados pelas áreas internas do hospital, visando a avanços no curto prazo. O quadro teórico foi desenvolvido a partir da literatura da teoria da visão baseada em recursos (RBV). Como objetivo específico pretendeu-se compreender se é possível hospitais com natureza jurídica de "fundação sem fins lucrativos", a partir de melhorias nos arranjos organizacionais e práticas de gerenciamento de seus processos internos, serem convertidos em centros de mais eficácia e obterem o reconhecimento público. Como resultado, verificou-se ser possível a formulação de uma estratégia de sucesso no segmento de saúde hospitalar, fundamentada na visão baseada em recursos (RBV).

PALAVRAS-CHAVE: Gestão hospitalar; Visão baseada em recursos (RBV); Estratégia organizacional.

\section{Hospital management through the Resource Based View (RBV)}

ABSTRACT: This article analyzes the experience of a Master Plan for Improvement of Hospital Management, developed and implemented during the year 2007, the Kidney and Hypertension Hospital. The aim of the project was to design an effective management model for the institution, covering both culture and the actions of the various services provided by the internal areas of the Hospital, seeking advances in the short term. The theoretical framework was developed from the literature of the theory of resource-based view RBV. Specific objectives sought to understand whether it is possible in the legal nature of Hospitals' Foundation non-profit, through improvements in organizational arrangements and practices for managing their internal processes, be converted into centers of greater efficiency, and gain recognition public. As a result, it proved possible to formulate a successful strategy within the segment of hospital health care, based on resource-based view RBV.

KEY WORDS: Hospital management; Resource-Based View (RBV). Organizational strategy.

\footnotetext{
* Submetido em 18 de Junho de 2012. Aceito em 04 de Dezembro de 2012. O artigo foi avaliado segundo o processo de duplo anonimato além de ser avaliado pelo editor. Editores responsáveis: Márcio Augusto Gonçalves e Lucas Maia dos Santos. Reprodução parcial ou total de trabalhos derivativos permitidos com a citação apropriada da fonte.
} 


\section{INTRODUÇÃO}

A literatura especializada em gestão vem considerando, para a compreensão das estratégias de uma empresa, principalmente a evolução dos ambientes organizacionais, cada vez mais marcados pelas inovações tecnológicas e pela crescente demanda dos consumidores por bons serviços. Particularmente no segmento de saúde hospitalar não é diferente, os altos níveis de incerteza e a grande quantidade de atores envolvidos (médicos, pacientes, órgãos reguladores, dentre outros) contribuem fortemente para que a mudança organizacional seja vista não como evento raro, mas como uma ocorrência cada vez mais frequente nesse tipo de organização, como um fator que impulsiona o seu desenvolvimento.

Procura-se neste artigo apresentar os fundamentos clássicos da visão baseada em recursos (RBV) e analisar de maneira empírica a sua aplicabilidade como instrumento de suporte aos processos de formulação de estratégia e gestão das organizações de saúde hospitalar.

Nesse contexto, o presente estudo objetiva responder a seguinte questão: como, e se é possível, hospitais com natureza jurídica de "fundação sem fins lucrativos", a partir de de melhorias nos arranjos organizacionais e práticas de gerenciamento de seus processos internos, podem ser convertidos em centros eficazes e obter o reconhecimento público, sob a lente do RBV?

O presente artigo foi estruturado em cinco seções, a primeira composta de introdução e breve contextualização das questões críticas de gestão e controle em hospitais. Segue-se a seção dois com a revisão teórica sobre a escola do posicionamento e da visão baseada em recursos (RBV). A seção três trata dos aspectos metodológicos e das fontes de coleta dos dados. O estudo de caso é apresentado na seção quatro, com breve histórico da instituição foco desta pesquisa, sendo descritos os diagnósticos e proposições de melhorias e discutidos os resultados práticos da aplicação das proposições de melhorias e destinação dos recursos. Por fim, são feitas na seção cinco as considerações finais e a conclusão do trabalho.

\subsection{Questões críticas de gestão e controle em hospitais}

De acordo com Druker (1999), o gerenciamento na área da saúde é mais complexo do que em qualquer outro tipo de organização, cujos objetivos de cada empresa atuante nesse segmento necessitam estar adequados à sua estrutura e às suas finanças.

Segundo Alves (1988), alguns dos principais objetivos na gestão hospitalar são identificar as oportunidades de melhorias e incentivá-las e, de outro lado, identificar quais os pontos que mais prejudicam o negócio e corrigi-los ou eliminá-los. Ainda para o autor, outro ponto importante é garantir que as decisões tomadas sejam implantadas dentro do escopo, prazo e custo; e assegurar também o passo seguinte, que as decisões sejam inseridas no funcionamento do dia-a-dia do hospital.

Corroborando essa afirmação, Gonçalves (2006) refere que, em um ambiente hospitalar, as decisões de mais impacto não conseguem ser viabilizadas se não tiverem o aceite direto dos responsáveis técnicos das áreas assistenciais, que são representadas pelos seus gestores, principalmente os médicos e enfermeiros-chefes, entre outros. Estes, convencidos da existência de fundamento lógico na proposição, tendo claras as relações lógicas de causa-efeito e suas consequências, atuam no hospital como disseminadores dessas novas idéias, patrocinando as mudanças na medida em que enxergarem os benefícios em se atingir um estágio mais avançado do modelo de controles operacionais.

Vendemiatti (2010), em seu estudo denominado "Conflito na gestão hospitalar", contextualiza o processo de profissionalização da gestão hospitalar e destaca os desafios para a atuação das lideranças para lidarem com a dimensão do conflito existente entre as subculturas médica, de enfermagem e administrativa. E conclui que a dinâmica hospitalar revela que o processo de inter-relações é produzido por uma complexidade de agentes que negociam a partir de diferentes lugares de poder, de especialização e de identidade organizacional.

A visão por unidade de negócios e por área é fundamental para identificar quais são os atendimentos prioritários para a instituição, respaldando as decisões, visando elevar o desempenho de cada unidade e, por consequência, da instituição como um todo (ROTTA, 2004). Essa visão propicia aos gestores estruturar indicadores adequados para a melhoria do desempenho do hospital.

Por outro ângulo, com base no trabalho de Dutta, Zbaracki e Bergen (2003), podem-se destacar as dificuldades na formação de preços dos diversos procedimentos hospitalares decorrentes de não consideração de todos os custos presentes no procedimento. O cálculo do preço final de um procedimento, na maioria dos casos, é insuficiente para cobrir toda a gama de complexidade das diversas etapas de insumos, acrescido dos custos com mão de obra envolvida, como um forte determinante para o desequilíbrio econômico-financeiro de uma instituição de saúde. 
Por fim, analisando-se a gestão pelo ponto de vista dos gastos e desperdícios, ressalta Borba (1982) que o maior ou o menor acúmulo de pequenas perdas durante o processo de atendimento está ligado a quanto maior for a falta de gestão administrativa sobre as variáveis de produção de um hospital, o que acaba por interferir negativamente no resultado geral da instituição. Ainda destaca que no hospital não há um único grande fator, que pode ser isolado e tratado para aperfeiçoar os resultados, mas o resultado final é sempre o somatório da melhoria dos processos parciais de todas as suas áreas, indivíduos e atividades.

\section{REFERENCIAL TEÓRICO}

As estratégias denominadas genéricas são aquelas advindas da interpretação de alguns autores como Porter (1986) e Mintzberg (1994), de ser possível determinar uma tipologia de estratégia com abrangência suficiente ampla para ser aplicada a qualquer tipo de indústria, independentemente do segmento, porte ou estágio de desenvolvimento de uma empresa. Destacam-se nas últimas décadas duas grandes linhas de pensamento estratégico que vem merecendo considerável atenção de pesquisadores

A primeira, baseando-se em "outside-in", de fora para dentro, com a ênfase da escola do posicionamento. Esta entende que o diferencial competitivo de uma empresa é fruto da estratégia, com foco em forças externas, em que a essência de uma estratégia competitiva é relacionar uma companhia ao seu ambiente. Assim, o aspecto principal do meio ambiente da empresa é a indústria ou as indústrias com que ela compete, o que tem recebido significativa aceitação ao longo das últimas três décadas, tendo Porter como um de seus expoentes.

A meta da estratégia de uma empresa é buscar uma posição em que possa melhor se defender da concorrência ou influenciá-la a seu favor (PORTER 1986). Ainda para o autor, o ambiente externo traduzido em forças competitivas como poder de barganha com fornecedores e clientes, rivalidade entre empresas, novos produtos e novos entrantes é que determina os direcionadores de valor de uma instituição, referindo-se à importância de como uma decisão operacional, tática ou estratégica (investimentos, crescimento das vendas, etc.), afeta o valor de uma empresa.

Outra linha de pensamento estratégico que vem merecendo considerável atenção de pesquisadores é a que entende a vantagem competitiva como fruto de fatores internos, "inside-out", de dentro para fora. Os fatores então relacionados às empresas individualmente exercem mais influência do que fatores externos oriundos da estrutura da indústria, que é denominada teoria dos recursos ou visão baseada em recursos (RBV).

De acordo com Penrose (2006), autora considerada precursora da teoria do RBV, em seu trabalho no desenvolvimento da "Teoria do crescimento da firma", cuja primeira publicação ocorreu no ano de 1959 , uma firma é definida como uma coleção de recursos e a influência do entorno está em um patamar secundário, visando permitir concentrar a análise nos recursos internos da firma. Segundo a autora, uma firma representa mais que uma unidade administrativa, trata-se de um conjunto de recursos produtivos cuja disposição entre os diversos usos e ao longo do tempo é determinada por decisões administrativas.

Ampliando essa visão, Wernerfelt (1984), em seu artigo considerado seminal sobre a RBV, afirma que recursos e produtos são dois lados de uma mesma moeda e olhar a empresa pelo lado dos seus recursos internos proporciona-lhe novas ideias (insights) além da visão proporcionada pelo lado dos produtos. Isso possibilita, também, obter melhores lucros com base na visão do correto balanceamento entre os recursos atuais e os a desenvolver.

Nessa mesma visão, afirma Barney (1991), não são todos os recursos que diferenciam uma empresa, mas somente aqueles heterogêneos, controlados pela empresa, constituídos de quatro características especiais:

a) Valiosos: capazes de promover a criação de valor.

b) Raros: escassos, de difícil obtenção pelos concorrentes e/ou novos concorrentes.

c) Imperfeitamente imitáveis: de modo que é difícil ou impossível para os concorrentes imitá-los, devido a dificuldades de dependência de caminho, ambiguidade causal e complexidade social que um recurso pode apresentar.

d) Imperfeitamente substituíveis: os consumidores não podem obtê-los de outros fornecedores nem substituí-los.

A proposta da RBV é de que as vantagens competitivas das empresas não são somente provenientes de combinações de produtos e mercados, mas principalmente de recursos internos e idiossincráticos das mesmas, que primariamente seriam as origens dos lucros ou superávit das empresas (GRANT 1991; BARNEY, 1991). 
Outro grupo inicial dessa corrente teórica dos recursos é derivado da escola de design estratégico de Andrews (1980), que apresenta o modelo de análise SWOT (acrônimo com origem nas quatro palavras do idioma inglês: forças, fraquezas, oportunidades e ameaças). Apregoa que, em geral, as forças e fraquezas de uma organização são resultados das forças e fraquezas dos indivíduos que a compõem e também da forma como essas capacidades individuais interagem com o trabalho coletivo e, por fim, da qualidade da coordenação dos esforços de melhoria contínua da equipe.

\section{METODOLOGIA}

Este trabalho fundamenta-se na abordagem qualitativa, a partir de fontes primárias e secundárias, quanto sua à tipologia em seu objetivo, e alinha-se aos conceitos apresentados por Raupp e Beuren (2003). Assim, trata-se de uma pesquisa de caráter exploratória, sendo enquadrada nessa categoria por refletir sobre um tema ainda pouco abordado em trabalhos anteriores.

Foi utilizada a metodologia de estudo de caso único que, segundo Yin (2010), a é adequada quando questões do tipo o que, como, e por que são aplicadas para a investigação de um fenômeno. Este estudo alinha-se justamente nesse sentido, procurando-se entender como o Hospital do Rim e Hipertensão organizou o seu conjunto de recursos e por que ele conseguiu, com melhorias nos arranjos organizacionais e prática de gerenciamento, obter uma administração eficaz e ser reconhecido como um centro de excelência ao atendimento da população.

A técnica de obtenção de dados empreendida foi a entrevista com os gestores das áreas-chave da instituição, composta conforme o Quadro 1, e, a partir disso, adicionalmente foram também analisados relatórios gerais da instituição, de interesse desta pesquisa, com a finalidade de obter informações complementares.

QUADRO 1. Qualificação dos respondentes da pesquisa.

\begin{tabular}{|c|c|c|c|}
\hline Respondente & Cargo & Responsabilidades & $\begin{array}{l}\text { Tempo de } \\
\text { empresa }\end{array}$ \\
\hline 1 & $\begin{array}{l}\text { Gerente Médico de } \\
\text { Pacientes Externos }\end{array}$ & $\begin{array}{l}\text { Médico Gestor, Responsável por todos os serviços a pa- } \\
\text { cientes externos da Instituição (Procedimentos que não ne- } \\
\text { cessitam de internação). }\end{array}$ & 11 anos \\
\hline 2 & $\begin{array}{l}\text { Gerente Médico de } \\
\text { Pacientes Internos }\end{array}$ & $\begin{array}{l}\text { Médico Gestor, Responsável por todos os serviços a pa- } \\
\text { cientes internados na Instituição. }\end{array}$ & 9 anos \\
\hline 3 & $\begin{array}{l}\text { Gerente } \\
\text { Operacional }\end{array}$ & $\begin{array}{l}\text { Administradora responsável por todos os serviços de infra- } \\
\text { estrutura de conforto a pacientes, envolvendo a rotina de } \\
\text { hotelaria hospitalar. }\end{array}$ & 2 anos \\
\hline 4 & $\begin{array}{l}\text { Diretor Técnico } \\
\text { Hospitalar }\end{array}$ & $\begin{array}{l}\text { Médico Gestor, Responde por assuntos técnicos de pesqui- } \\
\text { sa e gerenciais do Hospital, envolvendo atividades comple- } \\
\text { xas, na coordenação de profissionais de alta capacitação } \\
\text { técnica. }\end{array}$ & 14 anos \\
\hline 5 & $\begin{array}{l}\text { Gerente Administra- } \\
\text { tivo Financeiro }\end{array}$ & $\begin{array}{l}\text { Administrador Geral de assuntos financeiros, administrati- } \\
\text { vos, contábeis, e de recursos humanos, tanto a nível opera- } \\
\text { cional quanto a nível estratégico. }\end{array}$ & 8 anos \\
\hline
\end{tabular}

Fonte: Elaborado pelo Autor

De acordo com Gil (1999), a entrevista é uma técnica em que o investigador se apresenta frente ao investigado e lhe formula perguntas, com o intuito de obtenção dos dados que interessam à investigação.

Para a coleta de dados, foram executadas reuniões semanais de uma hora com os protagonistas do processo, descritos no Quadro 1, seguindo-se um roteiro previamente formulado com base na revisão da literatura.

Para orientar as conversas com os entrevistados, foi elaborado um protocolo de perguntas semiestruturadas. Queiroz (1988) ressalta que a entrevista semiestruturada é uma técnica de coleta de dados que supõe uma conversação continuada entre respondente e pesquisador e que deve ser dirigida por este último de acordo com seus objetivos, cujos tópicos foram pautados em quatro grupos principais.

Obter a opinião dos entrevistados a respeito de quais são as questões criticas na gestão e controle de instituições de saúde hospitalar, com o mesmo perfil do Hospital do Rim e Hipertensão:

a) identificar, a partir das entrevistas, os principais projetos de mudança ocorridos na instituição nos últimos anos (antes de 2007), suas implicações e resultados e se foram utilizados como baseline para futuras ações; 
b) colher a estrutura passo a passo do projeto;

c) identificar quais foram as principais proposições de melhoria dos processos de gestão da instituição, identificar quais foram implantadas durante o processo, detectando também os principais direcionadores de valor da instituição;

d) colher os resultados finais e perceber se a destinação futura dos recursos foi alinhada à vocação/ missão da instituição.

A partir dos resultados obtidos nessas diversas fontes, foi possível desenvolver o estudo de caso.

\section{O ESTUDO DE CASO}

\subsection{Breve histórico da instituição foco da pesquisa}

Em meados de 1983, os professores e orientadores da disciplina Nefrologia, da Universidade Federal de São Paulo (Unifesp), fundaram o Instituto Paulista de Estudos e Pesquisas em Nefrologia e Hipertensão (IPEPENHI), transformado agora em Fundação Oswaldo Ramos (FOR), entidade jurídica de direito privado e sem fins lucrativos, com a finalidade de prover a sustentabilidade de suas ações sociais de saúde e pesquisa.

O impacto social da Fundação Oswaldo Ramos ultrapassou todas as expectativas iniciais. A capitalização dos recursos gerados mais o reconhecimento pelos órgãos públicos proporcionaram a construção do Hospital do Rim e Hipertensão (HRH).

A entidade tem 108 leitos, sendo nove de unidade de terapia intensiva (UTI) e 99 entre apartamentos e enfermarias, com vocação pública. Disponibiliza mais de $80 \%$ de sua atenção a casos de elevada complexidade médica para a população atendida pelo Sistema Único de Saúde (SUS).

Tornou-se centro hospitalar de utilidade pública em nível municipal, estadual e federal com o mais alto número de transplantes renais do mundo, realizando quase há uma década entre 500 e 600 transplantes por ano. Ao lado disso, o HRH ofereceu para a população do SUS 2.750 internações, 470 mil exames laboratoriais e 136 mil atendimentos ambulatoriais, em média, por ano, no período de 2007 a 2010.

\subsection{Diagnósticos, proposições e implantação de melhorias de gestão no Hospital do Rim e Hipertensão}

\section{$1^{\circ}$ momento: concepção estratégica do Hospital do Rim e Hipertensão}

Validação da missão e do negócio, definição da visão e identificação dos princípios norteadores da ação.

Nesta etapa foi considerada a proposta metodológica de Chiavenato e Sapiro (2003), que define o planejamento estratégico como um processo de formulação de estratégias organizacionais no qual se busca a inserção da organização e de sua missão no ambiente em que ela está atuando. De fato, a "alta direção" do hospital procedeu a um trabalho de revalidação da missão, da visão, dos valores e do negócio, corroborando a visão já firmada desde a sua fundação de que a instituição deve "promover a excelência na assistência e na busca contínua de tratamento e prevenção das doenças de rim e da hipertensão arterial em benefício da população, como o maior centro de referência em transplantes de rim em nível nacional e internacional".

\section{$2^{\circ}$ momento: da utilização de ferramentas estratégicas de diagnóstico}

Houve a revisão da análise dos ambientes interno e externo, que foi realizada por meio da matriz SWOT, seguindo como critério a atualização de um plano de ação anterior, do ano de 2006 . Sua realização foi feita por meio de oficinas internas para a elaboração do Plano Diretor de Melhorias na Gestão Hospitalar para o triênio 2007-2009, tendo a participação do grupo gestor composto de dois diretores, três gerentes - um da área técnica, outro da área assistencial e o último da área administrativa do hospital -, coordenadores de departamentos e convidados, como gestores municipais da microrregião. Objetivou-se a construção do diagnóstico situacional do município e da instituição, bem como a revisão de qual é o negócio da instituição, da missão, da visão estratégica e dos princípios e valores praticados e/ou a serem implantados.

A escolha das áreas para a realização das análises de ambiente interno e externo deu-se também por meio da metodologia SWOT e teve como critério os gargalos ou nós críticos da instituição. A solução dessas dificuldades propicia uma gestão profissionalizada e efetiva. Ao mesmo tempo, foram identificados os fatores críticos de sucesso da instituição, também chamados de determinantes de sucesso, que servem de base para fortalecer a organização para o alcance das diretrizes e metas estratégicas que ela vai definir para si no planejamento estratégico. 
Alguns fatores críticos identificados para o sucesso do Hospital do Rim são: gestão profissionalizada, equilíbrio financeiro, qualificação e capacitação dos profissionais, processos internos mapeados, sistematizados e implantados, hotelaria hospitalar, entre outros.

Com base nessa análise institucional, foram elaboradas as estratégias globais de ação e uma avaliação de prioridades a serem incluídas. Para a análise das prioridades, utilizou-se a metodologia GUT (ALMEIDA, 2005), que significa gravidade, urgência e tendência. Seguindo o processo, foram avaliadas as situações em cada área-chave sob seus aspectos de fortalezas, oportunidades, fraquezas e ameaças, seguidas das estratégias de ação propostas.

\section{$3^{\circ}$ momento: formulação estratégica, achados e pressupostos}

Houve a análise e consolidação do material recebido e obtido em relação às questões externas e internas, buscando-se identificar os fatores positivos internos e as oportunidades futuras para o hospital, assim como os fatores negativos, ou seja, aqueles que ameaçam ou podem ameaçar, externa e internamente, os esforços da organização para alcançar o desenvolvimento e a competitividade estratégica.

Nessa fase a influência do "entorno" foi posta de certa maneira de lado numa primeira instância, com vista a permitir concentrar a análise nos "recursos internos" da instituição, adotando-se como premissa que melhorias operacionais na gestão rapidamente contribuem e fortalecem o resultado econômico-financeiro de hospitais. O trabalho priorizou três pontos principais: redução de custos, aumento de receitas e melhorias das atividades de gestão e controle.

Como fruto desse trabalho, ligados a fatores positivos internos e às oportunidades futuras para o hospital, chegou-se à conclusão de que os ganhos de receita são os que contribuem com a maior fatia no total de melhorias obtidas, seguida por ações de gestão e controle. Os pontos priorizados para revisão e melhora foram compostos dos seguintes itens:

1. Políticas de faturamento.

2. Redução de glosas aplicadas pelas operadoras de saúde.

3. Precificação de serviços médicos e pacotes padronizados.

4. Redução de tempo de permanência de paciente internado, mais giro de leitos.

5. Controle da média de permanência dos pacientes internados, pois, segundo Filho (2003), a diminuição dessa média proporciona ao hospital o aumento do giro dos pacientes nos leitos, favorecendo, assim, um incremento no valor da receita produzida pelo aumento das internações.

6. Redimensionamento para o investimento de ativos e equipamentos.

7. Estreitamento do relacionamento e fidelização do médico junto à instituição e plano de incentivo aos médicos.

8. Equacionamento da redução de custos sem perda de qualidade.

9. Redimensionamento do quadro de pessoal, buscando a redução de horas extras e absenteísmo.

10. Revisão e renegociação de contratos com terceiros.

11. Priorização para internação, com a finalidade de dar exclusividade a transplantes renais e às doenças de nefrologia, metabologia e cardiovasculares.

12. Redução de custos com material e medicamento, a partir do balanceamento de estoques de material e medicamento.

13. Redução de desperdícios, em todos os níveis.

14.Política de compras associada à redução de custos, de acordo com a Lei 8.666/93.

$4^{\circ}$ momento: formulação estratégica, elaboração do Plano Diretor de Melhorias na Gestão do Hospital

Envolvendo os gerentes, o corpo clínico, a direção e os representantes do Conselho de Administração do hospital, foi realizado o Seminário de Formulação Estratégica, o que propiciou a análise e o desenho de cenários, a identificação dos fatores críticos de sucesso do hospital, a investigação acurada dos resultados externos e internos obtidos, a elaboração do diagnóstico e a identificação de macrodiretrizes estratégias institucionais. Posteriormente, em reunião, o grupo gestor concluiu o Plano Diretor de MeIhorias na Gestão do Hospital, complementando o desdobramento das diretrizes e estratégias.

Sob a orientação do grupo gestor, foi então repassado aos gerentes das unidades o resultado, para que procedessem ao planejamento tático e operacional, ou seja, à identificação das medidas de ação e à elaboração dos planos de ação correspondentes.

\section{$5^{\circ}$ momento: implantação estratégica, monitoramento e avaliação de resultados}

Mesmo sendo o acompanhamento e monitoramento de resultados uma prática já inerente às atividades do hospital, o grupo gestor definiu para esse Plano Diretor de Melhorias na Gestão do Hospital a 
implantação das ações e um processo contínuo de avaliação dos resultados, com identificação de contramedidas estratégicas de inovação ou melhorias, que deveriam ocorrer no período de 2007 a 2009.

Os resultados econômico-financeiros obtidos por meio do novo modelo de gestão do Hospital do Rim e Hipertensão, quando colocados em prática já durante o ano de 2007, alcançaram expressivos benefícios no aumento de receitas e na diminuição de despesas. Esses benefícios foram colhidos parte no segundo semestre de 2007, parte no primeiro semestre 2008, com reflexos positivos até os dias de hoje.

GRÁFICO 1. Aumento de receitas no ano de 2007, em relação a 2005 e 2006.

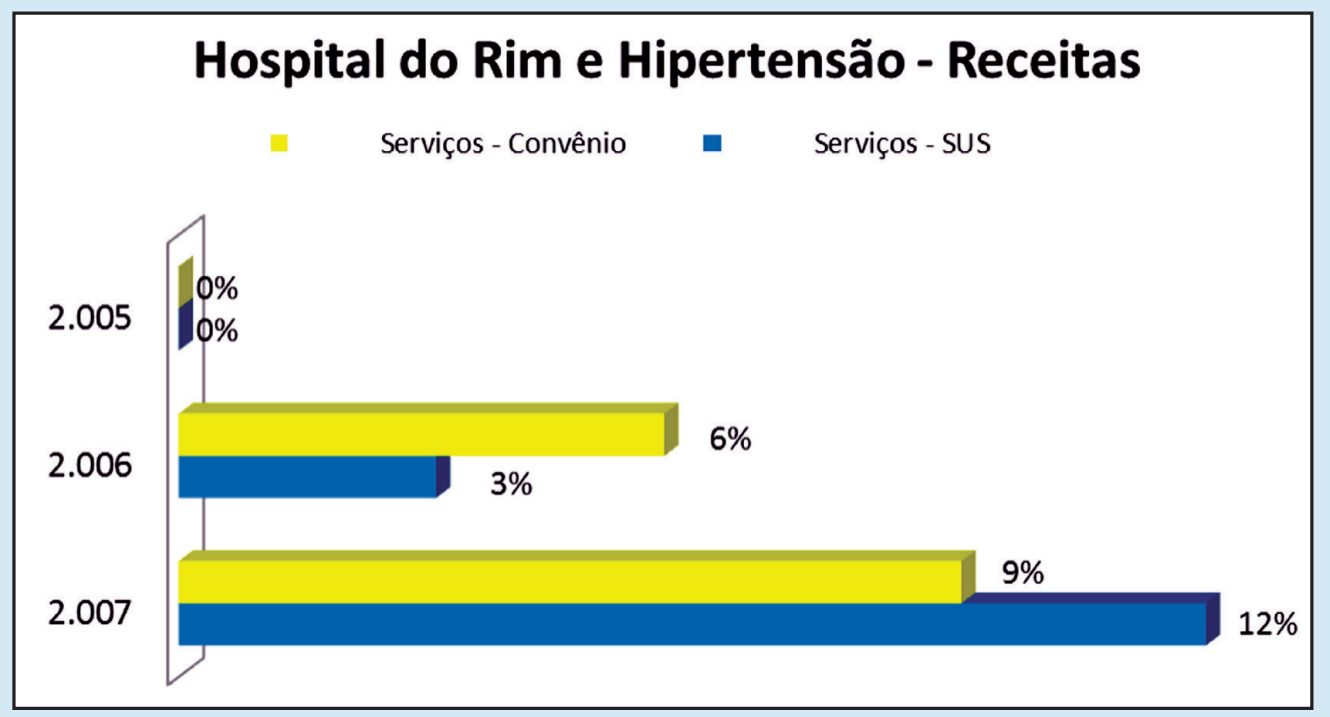

Fonte: Dados secundários da instituição.

GRÁFICO 2. Diminuição de despesas no ano de 2007, em relação a 2005 e 2006.

\section{Hospital do Rim e Hipertensão - Despesas}

Material e Medicamento $\quad$ Serviços Terceirizados e de Consultoria.

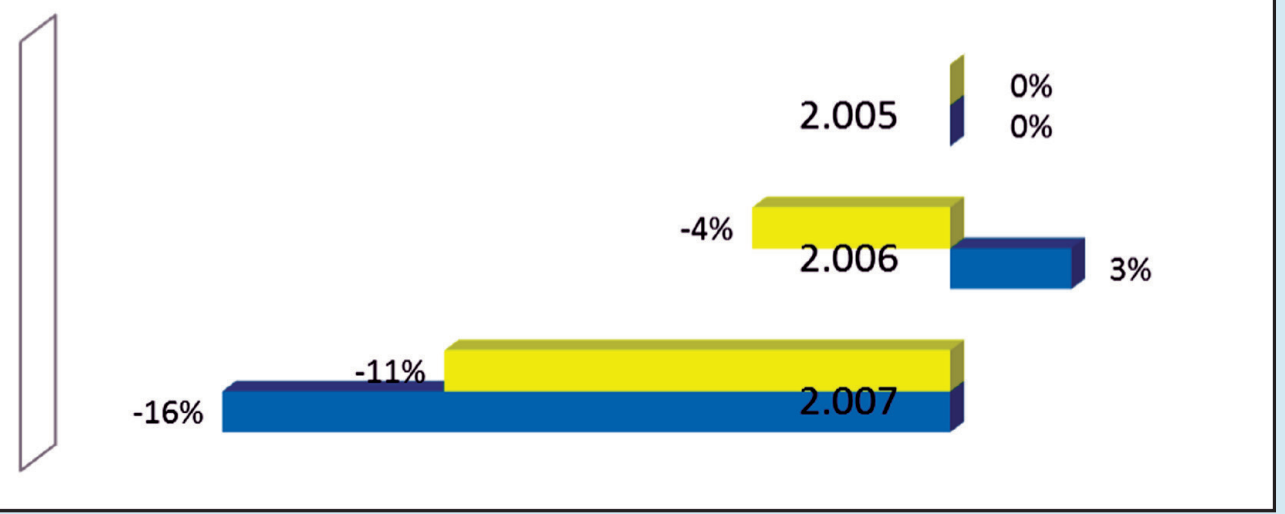

Fonte: Dados secundários da instituição.

A destinação dos resultados obtidos com o fortalecimento econômico-financeiro da instituição foi canalizada para o enriquecimento dos recursos e capacidades internas da instituição em dois polos principais: recursos humanos e recursos organizacionais. Esse fato é alinhado ao pensamento de Barney (1991).

Ambos os polos foram traduzidos em ações que reforçaram a vocação da instituição no atendimento à população de baixa renda; foram criados e melhorados significativamente no hospital diversos programas, como o Programa de Arte e Terapia, programas de atividade de relaxamento, voluntariado, 
ouvidoria institucional, acolhimento com avaliação de risco e prioridade de atendimento, investimento de adequação de área física para conforto de usuários, familiares e funcionários, criação de equipes interdisciplinares de referência para pacientes e familiares, ampliação da política de acompanhantes para todos os pacientes, investimento em programas de qualidade em conformidade com as normas reguladoras da Organização Nacional de Acreditação (ONA) e programas de formação e reciclagem profissional para equipes médicas, de suporte assistencial e administrava (adaptado de documento interno: Plano Operativo de Contratualização do Hospital do Rim - 2007).

Por fim, é relevante destacar que tais melhorias também refletiram positivamente na produção do Hospital do Rim e Hipertensão em seu principal serviço à população de baixa renda, que é o transplante de rim, com evolução positiva na ordem de 16\% entre os anos 2007 e 2008.

TABELA 1. Evolução de transplantes, principal serviço prestado pelo hospital, de 1998 a 2008.

\begin{tabular}{lcccccccccccc} 
Transplante & 1998 & 1999 & 2000 & 2001 & 2002 & 2003 & 2004 & 2005 & 2006 & 2007 & $2008^{*}$ & Total \\
\hline Total ano acumulado & 109 & 393 & 443 & 486 & 464 & 490 & 618 & 575 & 603 & 610 & 707 & 5.498
\end{tabular}

Fonte: Dados secundários da Instituição.

* Realizado até nov./2008.

\section{CONSIDERAÇOES FINAIS}

De modo geral, as melhorias advindas com o projeto do Plano Diretor de Melhorias na Gestão do Hospital contribuíram nesse contexto para a construção de ferramentas de racionalização dos processos de gestão da instituição, melhor alocação dos recursos disponibilizados, incremento na capacitação sistemática do pessoal técnico, melhor equilíbrio financeiro da instituição, atendimento eficiente, com qualidade e resolutividade, além da manutenção da instituição no mercado em condições de competitividade e perpetuidade.

Podem-se identificar a adequação, entre o estudo de caso apresentado, e a teoria do RBV, cuja melhoria na gestão foi gerada predominantemente por meio de competências e recursos internos baseados, por exemplo, na melhoria de rotinas e processos internos. Esta última, nesse âmbito, transforma-se em um recurso de valor, raro, de imperfeita substituição e replicação (GRANT 1991; BARNEY, 1991), liberando tempo e otimizando os recursos financeiros para serem aplicados na atividade principal da instituição, no tratamento e prevenção das doenças de rim e da hipertensão arterial, em benefício da população.

Os benefícios para a organização, mesmo no curto prazo, foram visíveis em várias áreas, principalmente nos processos-chave relacionados aos pacientes da instituição, detalhados na seção 4.2 deste estudo, que culminaram no reconhecimento público, colocando o Hospital do Rim e Hipertensão entre os 10 melhores hospitais do SUS de São Paulo na avaliação dos usuários.

Pesquisa da Secretaria da Saúde revelou, pela primeira vez na história, o ranking dos 10 melhores hospitais e as cinco melhores maternidades públicas do estado de São Paulo na avaliação dos usuários do SUS. O levantamento, conforme o Quadro 2, ouviu 60.200 pacientes que passaram por internações e exames em cerca de 500 estabelecimentos de saúde conveniados à rede pública paulista nos meses de novembro e dezembro de 2007 e abril e junho de 2008.

QUADRO 2. Os 10 melhores hospitais do SUS de São Paulo na avaliação dos usuários.

\begin{tabular}{|c|c|c|}
\hline Município & Nome & Notas \\
\hline São Paulo & 1. HOSPITAL DO RIM E HIPERTENSAO & 9,349 \\
\hline Ribeirão Preto & 2. HOSPITAL DAS CLINICAS FAEPA RIBEIRAO PRETO & 9,345 \\
\hline Marília & 3. HOSPITAL DAS CLINICAS UNIDADE MATERNO INFANTIL & 9,342 \\
\hline Jaú & 4. HOSPITAL AMARAL CARVALHO JAU & 9,335 \\
\hline São Paulo & 5. FUNDACAO ADIB JATENE & 9,333 \\
\hline Bauru & 6. HOSPITAL DE REABILITACAO DE ANOMALIAS CRANOFACIAIS BAURU & 9,331 \\
\hline São Paulo & 7. HC DA FMUSP INSTITUTO DO CORACAO INCOR & 9,300 \\
\hline São Paulo & 8. INST BRASILEIRO DE CONTROLE DO CANCER IBCC & 9,297 \\
\hline São Paulo & 9. HOSPITAL ESTADUAL DE VILA ALPINA ORG SOCIAL SECONCI & 9,290 \\
\hline São Paulo & 10. HOSPITAL SAO JOAQUIM BENEFICENCIA PORTUGUESA & 9,288 \\
\hline
\end{tabular}

Fonte: Portal do Governo do Estado de São Paulo (2008). 
Por fim, acredita-se, assim, que este trabalho tenha alcançado os objetivos propostos inicialmente, respondendo a questão de pesquisa formulada, trazendo contribuição prática com aplicação teórica, por meio da demonstração dos resultados de um estudo de caso que respondeu ser, sim, possível que as mudanças organizacionais de uma instituição de saúde hospitalar a partir de seu estoque de recursos internos leve a uma administração eficaz e seja reconhecida publicamente.

Embora este trabalho não esgote esse assunto, os resultados positivos alcançados nessa empreitada feita pelo Hospital do Rim e Hipertensão indicam a eficácia estratégica desse modelo gerencial na administração, que pode servir de base para outras instituições de saúde, tanto públicas quanto da iniciativa privada, na busca por excelência na gestão hospitalar.

\section{REFERÊNCIAS}

ANDREWS, K. R. The concept of corporate strategy. In: The strategy process: concepts, contexts and cases. 2 ed. Englewood Cliffs: Prentice-Hall, 1991. p. 44-52.

ALMEIDA, A. M. Planejamento e estratégia situacional. Juiz de Fora: FEA/UFJF, 2005.

ALVES, A. Fontes de financiamento e eficiência em dois hospitais privados e filantrópicos paulistas: um estudo de caso. Tese (Doutorado) - Faculdade de Saúde Pública, Universidade de São Paulo, 1988.

BARNEY, J. B. Firm resources and sustained competitive advantage. Journal of Management, v. 17, n. 1, p. 99-120, 1991.

BORBA, V. R. A. A importância da avaliação e controle da administração hospitalar. O mundo da saúde, v. 6, n. 22, p. 79-84, 1982.

CHIAVENATO, I.; SAPIRO, A. Planejamento estratégico: fundamentos e aplicações. Rio de Janeiro: Elsevier, 2003.

DUTTA, S.; ZBARACKI, M.; BERGEN, M. Pricing Process as a Capability: a Resource-Based Perspective. Strategic Management Journal, v. 24, n. 7, p. 615-630, 2003.

DRUKER, P. Desafios Gerenciais para o século XXI. São Paulo: Pioneira, 1999.

FILHO, J.C.S. Alternativa de Redução de Custos Hospitalares Através da Redução da Média de Permanência em um Hospital Público de Urgência e Emergência na Área do Trauma. VIII CONGRESSO INTERNACIONAL DE CUSTOS, 10, 2003, Uruguai.

GONÇALVES, E. L. Gestão hospitalar: administrando o hospital moderno. São Paulo: Saraiva 2006.

GIL, A. C. Métodos e técnicas de pesquisa social. 5. ed. São Paulo: Atlas, 1999.

GRANT, R. M. The resource-based theory of competitive advantage: implications for strategy formulation. California Management Review, v. 33, n. 3, p. 114-135, 1991.

MINTZBERG, $\mathrm{H}$. The fall and rise of strategic planning. Harvard Business Review, v. 72, n. 1, p. $107-$ 114, 1994.

PENROSE, E. A teoria do crescimento da firma. Campinas: Unicamp, 2006. p. 45-123.

SÃO PAULO. Plano Operativo de Constratualização. Hospital do Rim e Hipertensão. São Paulo: Secretaria Municipal de Saúde do Estado de São Paulo, 2007.

SÃO PAULO. Secretaria da Saúde. Portal do Governo do Estado de São Paulo. Disponível em: http:// www.saude.sp.gov.br/ses/noticias/2009/marco/provao-do-sus-elege-os-15-melhores-hospitaispublicos-de-sao-paulo. Acesso em: maio de 2009.

PORTER, M. E. Estratégia competitiva: técnicas para análise de indústrias e da concorrência. 7 ed. Rio de Janeiro: Campus, 1986. p. 12-123.

QUEIROZ. M. I. P. Relatos orais do indizível ao dizível. São Paulo: Vértice, 1988. p. 68-80.

RAUPP, F. M.; BEUREN, I. M. Como elaborar trabalhos monográficos em contabilidade: teoria e prática. São Paulo: Atlas, 2003.

ROTTA, C. S. G. Utilização de indicadores de desempenho hospitalar como instrumento gerencial. 2004 Teses (Doutorado) - Faculdade de Saúde Pública, Universidade de São Paulo, 2004.

VENDEMIATTI, M.; SIQUEIRA, E. S. Conflito na gestão hospitalar: o papel da liderança. Ciência e Saúde Coletiva, v. 15, supl. 1, p. 1301-1314, 2010.

WERNERFELT, B. A resource-based view of the firm. Strategic Management Journal, v. 5, p. 171-180, 1984.

YIM, R. K. Estudo de caso: planejamento e métodos. 2. ed. Porto Alegre: Bookman, 2010. 